\title{
Mapping wind resources and extreme wind: Technical and social aspects
}

Xiaoli Guo Larsén,' Rong Zhu² and Russell Mckenna3,4

'DTU Wind Energy; ${ }^{2}$ National Climate Centre, CMA; ${ }^{3}$ DTU Management; ${ }^{4}$ University of Aberdeen

\section{Introduction}

Over the past decade, renewable energy has become an important player in global energy and development policy, providing 62\% of new power generating capacity (IRENA 2020). Wind energy grew from $13 \%$ to $24 \%$ of global renewable energy capacity from 2009 to 2018 (IRENA 2019). To ensure climate protection and sustainable development, the International Renewable Energy Agency (IRENA) calculates that renewables, including wind, must grow four times faster than this by 2030 (IRENA 2020).

Supporting political and economic decision-makers at all levels requires detailed data on the spatial and temporal resolution of wind resources and siting conditions. As well as the wind conditions themselves, the suitability of local environments for exploiting this resource needs to be considered. Against this background, this chapter presents an overview of methodologies for making assessments of wind resources and extreme winds respectively. This is accompanied by a general overview and a focus on studies applied to China, followed by a consideration of knowledge gaps and the outlook for the future. Then the non-technical aspects of assessing wind resources are presented, again presenting the state of the art and identifying gaps in knowledge. Finally, a brief summary and outlook for both the technical and non-technical aspects is provided.

\section{Mapping wind resources}

\section{Development of methodologies and applications}

\section{In general}

In the 1970s and 1980s, the development of wind energy was rather local and small in scale, mostly occurring in a few windy European countries, including Denmark. The methodologies for installing wind turbines were mainly linked to a number of civil-engineering functions, as in the case of buildings, bridges and air pollution etc. One essential methodology for assessing wind resources has been to use mast measurements in a particular area or site. The aim of the European Wind Atlas (EWA) was to establish the meteorological basis for assessing wind resources in Europe. Along with the publication of the EWA (e.g. Troen and Petersen 1989), the wind atlas method was developed as a microscale program for wind resource assessment, WAsP! In making the atlas with the aid of this program, some two hundred meteorological stations were used all over Europe.

The wind-atlas method became a foundation for the further development of methodologies, which it still is. It helped set a standard for reasonable local measurements for planning new wind-farms. This requirement has accelerated the latest development of measuring techniques, such as remote sensing LIDAR² (e.g. Mann et al. 2017). At the same time, given the rapid expansion of the wind-energy industry, both farms and turbines are growing in rated capacity and physical size, so that it becomes more challenging and expensive to collect measurements in order to cover both the horizontal and high-altitude wind conditions. Accordingly, numerical modelling is assuming an increasingly important role in making wind-resource assessments. Most peer-reviewed methodologies use both measurements and modelling, their respective roles varying in different applications.

Methods with a high level of emphasis on the use of measurements also include those using satellite products (e.g. Badger et al. 2016; Hasager et al. 2020). The satellite data method is still challenged in some areas by sample size, resolution and quality at strong wind speeds.

In both onshore and offshore environments, the mainstream method is numerical modelling, assisted by measurements. Depending on its resolution, ${ }^{3}$ numerical modelling can have grid spacing from hundreds to tens to a few km, down to $1 \mathrm{~km}$ scales. In line with the atlas method, the wind input required for high resolution modelling around the turbine site has been calculated from coarser modelled data. One such approach is the KAMM ${ }^{4} /$ WAsP method (Frank et al. 2001, Badger et al. 2014). Wind distributions calculated as classes of speed, direction and stability are first prepared using long-term, coarse-resolution reanalysis data from global circulation models (GCM) with a resolution of $100 \mathrm{~km}$. These classes of wind are downscaled to the mesoscale using KAMM, with a resolution of a few km,

\footnotetext{
l www.wasp.dk

2 Light Detection and Ranging

3 Model grid spacing. A grid spacing of $1 \mathrm{~km}$ gives a grid size of $1 \mathrm{~km} \times 1 \mathrm{~km}$

4 Karlsruhe Mesoscale Model, a static mesoscale model.
} 


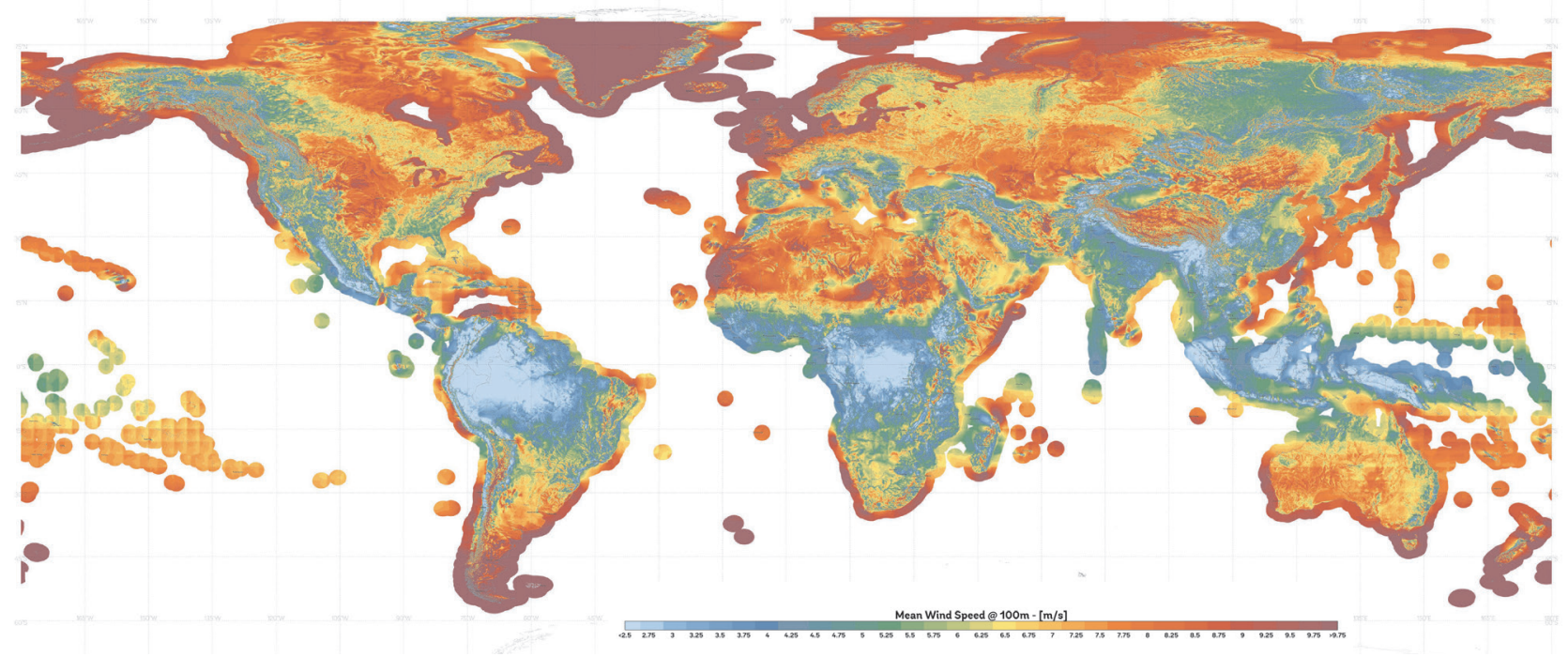

Figure 1 Map of mean wind speed at 100 m in m s-1 from the Global Wind Atlas III project. This map has been prepared by the Technical University of Denmark and Vortex FdC S.L. (VORTEX), under contract to the World Bank. The map can be obtained from https://globalwindatlas.info.

before they are further downscaled using microscale modelling of WAsP with a resolution of tens of meters. This method has been used to generate atlases of many regions and countries, including Europe, Egypt, Finland and part of China, as reported in, for example, Mortensen et al. (2006), Badger et al. (2010) and Tammelin et al. (2013). With larger and larger computation facilities becoming available, the dynamical downscaling of global circulation data to a few kilometres has become possible. In the New European Wind Atlas project, thirty years of weather data have been downscaled using the Weather Research and Forecasting (WRF) model down to a resolution of $3 \mathrm{~km}$ all over Europe (e.g. Hahmann et al. 2020). Wind climate generated from this dataset has been used in WAsP to obtain wind-resource estimates at resolutions of a few hundred meters. ${ }^{5}$ Fig. 1 shows a map of mean wind speeds at 100 $\mathrm{m}$ over the globe from the Global Wind Atlas III project, which was derived from a chain of models, with winds from the ERA56 reanalysis data (approximately $30 \mathrm{~km}$ ) being downscaled to $3 \mathrm{~km}$ through WRF modelling and further downscaled to 250 m using WAsP software.

Besides the atlas method, numerical modelling data have also been used together with measurements made in other ways. The WIND Toolkit from Draxl et al. (2015) combines seven-year high resolution (2 km, 5 min) WRF model output with site-appropriate turbine power curves to estimate the power produced at each of the turbine sites in the US. Using limited in-situ measurements to 'adjust' the modelled data constitutes a simplified form of site-modelling, with similar aims to microscale modelling, except that it is highly empirical. The philosophy is

\footnotetext{
5 https://globalwindatlas.info

6 The 5th generation of ECMWF's atmospheric reanalyses of the global climate.
}

to combine the long-term statistics in the modelled data and the site-specific variability in the measurements. In Delle Monache et al. (2013), this concept was applied to assessments of wind resources. Measurements have also been used to assist in designing more cost-effective long-term simulations. For instance, in Fischereit and Larsén (2020), about 180 days of data were collected based on tens of sites of measurements over the southern North Sea that are able to represent thirty-year climatological statistics of wind and waves. Thus, the computation cost of performing high-resolution calculations is significantly reduced. The 'weather classification' method, as described below for wind resource studies in China, is another example of decades of data being condensed into a limited number of days.

\section{In China}

In the case of China, there are two aspects to assessing wind resources. One relates to planning, where maps of wind resources are used to draw up policies for the development of wind energy and make preliminary selections of sites for wind farms. The other aspect is the development of a coupling technology between mesoscale models and CFD models in designing wind farms.

In mapping wind resources, the key technical issues are on the one hand how to improve the spatial and temporal resolution of the distribution of wind resources, and on the other hand how to calculate the longterm average wind-speed distribution over twenty to thirty years and related statistical parameters for wind resources cost-effectively. In order to do this, in 2010 the China Meteorological Administration developed the Wind Energy Resources Assessment System (Zhu et al.

7 Computational Fluid Dynamics Model. 
Table 1 Standard assumptions for GIS analysis of available areas for wind development relating to Figure 2.

\begin{tabular}{cccc} 
Slope (\%) & Area available in category & Land Use & Area available in category \\
\hline$\alpha \leq 3$ & $100 \%$ & Natural reserve & $0 \%$ \\
\hline $3<\alpha \leq 6$ & $50 \%$ & Water & $0 \%$ \\
\hline $6<\alpha \leq 30$ & $30 \%$ & Grassland & $80 \%$ \\
\hline$>30$ & $0 \%$ & Shrub & $65 \%$ \\
\hline & & Forest & $20 \%$ \\
\hline & & Distance to urban area $\leq 3 \mathrm{~km}$ & $0 \%$ \\
\hline
\end{tabular}
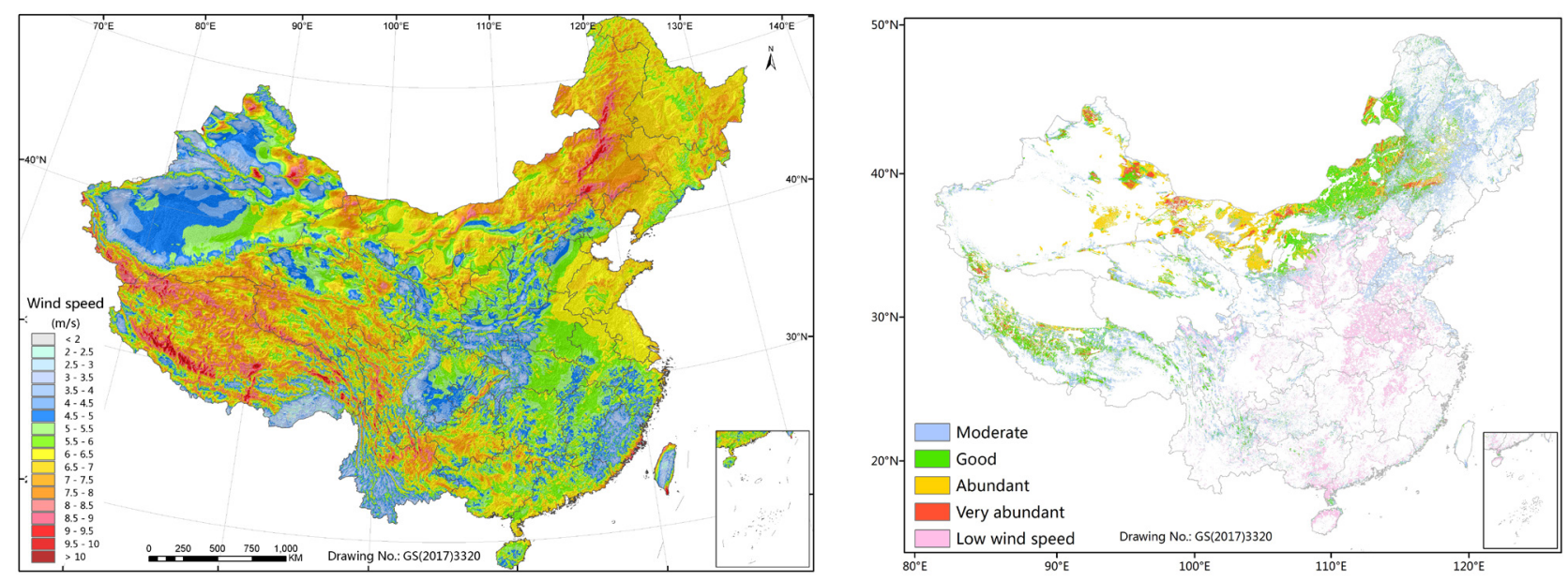

Figure 2 Spatial distribution of (a) annual mean wind speeds and (b) exploitable wind energy resources at $100 \mathrm{~m}$ above ground across China. .

2010, CMA 2014). A combination of a mesoscale model with microscale models is used to obtain a refined wind map showing climatic averages through the numerical simulation of a limited number of samples. The system is composed of three parts: weather classification, mesoscale and microscale numerical simulation, and Geographical Information System (GIS) analysis. In addition, a wind dataset with a resolution of $1 \mathrm{~km}$ was created that represents the long-term climate statistics of wind resources from 1979 to 2008. Figure 2 shows the spatial distribution of annual mean wind speeds and exploitable wind energy resources at $100 \mathrm{~m}$ all over China, with key analysis summarized in Table 1 (Zhu et al. 2020). According to the technical and economic conditions and policies, some areas, such as slopes greater than 30\%, bodies of water, urban areas, national and state parks, and lands reserved for military use, should be excluded. Some areas cannot be used fully for wind development: for example, grass can be used up to $80 \%$, shrub $65 \%$, forest $20 \%$, etc. In the figure of the distribution of exploitable wind resources, all the areas in colour are those that are available for wind farms, while the areas in white are not available. Wind distribution with a horizontal resolution of $50 \mathrm{~m}$ by $50 \mathrm{~m}$ or finer and a time resolution of 1 hour is favourable for resource assessments for a windfarm design. To simulate the proposed wind farm, using high-fidelity numerical simulation methods coupled with a mesoscale model and CFD is the most effective and is focus of current technological developments. In China, a wind-forecasting method for wind farms has been developed (Ma et al. 2016).

Two wind-resource datasets are available for China: the long-term averaged high spatial resolution dataset, and the long-term series high spatial and temporal resolution data set. The former has a horizontal resolution of $1 \mathrm{~km} \times$ $1 \mathrm{~km}$, which represents the climatic average and statistical characteristics of wind resources in 1979-2008, and can be used to assess national or regional wind-energy potential and to provide a scientific basis for planning wind-power development. For example, the analysis results of this dataset of wind-energy resources has been approved by the National Development and Reform Commission and the International Energy Agency's '2050 China Wind Power Development Roadmap', the IPCC' $\mathrm{s}^{8}$ 'Renewable Energy and Mitigation of Climate Change Special Report', the Chinese Academy of Engineering and 'China Energy Medium and Long Term (2030, 2050) Development Strategy Research'. The

8 International Panel for Climate Change. 
long-term series high spatial and temporal resolution dataset has a horizontal resolution of $3 \mathrm{~km} \times 3 \mathrm{~km}$ and spatial resolution of 1 hour from 1995 to 2016. It can be used to start CFD modelling for wind-farm design and also to provide a database for wind energy enterprises and related technical advisory bodies. For example, enterprises such as the China State Shipbuilding Corporation Limited, the China Railway Rolling Stock Corporation, GoldWind and so on, have used these data to provide wind farm siting services to their customers.

\section{Knowledge gaps and outlook}

In all the approaches discussed above, efforts are made to resolve site-specific conditions. Downscaling to the microscale is both scientifically and technically challenging (e.g. Veers et al. 2019), despite which it represents a common, ongoing effort to bridge mesoscale flows with microscale flows. Another factor that is ceasing to be negligible is the wake effect from wind parks when estimating the available resources in an area, which, with normal spacing, can cause a power reduction of up to $10 \%$ in the neighbouring area. Currently, the most frequently applied and investigated method is the open-source WRF model, which has two primary parameterization schemes available: the Fitch scheme (Fitch et al. 2012) and the EWP scheme (Volker et al. 2015). Another ongoing research topic is how to merge the large-scale, farm-scale wake with the smallscale, turbine-scale wake (e.g. Porte-Agel et al. 2019), which is relevant for the more accurate modelling of wind resources.

\section{Mapping extreme winds}

\section{Development of methodologies and applications}

\section{In general}

With climate change, an increase has been observed in the intensity and frequency of some extreme weather conditions. Extreme weather causes a number of challenges in both the design and operation of wind turbines. Storms are often associated with strong winds, affecting the turbine's load and fatigue. The highly variable flow, with reference to the cut-out speed of, for example, $25 \mathrm{~ms}^{-1}$ (the speed at which the turbine is shut down), can cause large fluctuations in power production, which accordingly affects the power integration system. Here, extreme wind methodology development is analysed, for example, of fifty-year extreme wind at hub height, which is a design parameter specified in the IEC 9 standard 61400-1 (IEC 2007), as required for windfarm planning. This parameter needs to be calculated to find suitable turbines for each farm in order to harvest the most wind energy while reducing the risk of damage from harsh wind conditions.

The earliest dataset of fifty-year wind was produced in line with general civil-engineering applications and was

9 International Electrotechnical Commission based on in-situ measurements, such as the European Wind Load Code (Eurocode 1995). In this code, many European countries made their own extreme-wind maps using different approaches (e.g. Miller 2003, Larsén and Mann 2009). As a result, there is significant discontinuity in extreme wind values at national borders.

The development of methodologies for estimating extreme wind can be sorted into the following categories: (a) statistical functions for region-specific extreme wind climates; (b) long-term measurements of pressure; and (c) numerical modelling approaches.

For category (a), one needs to determine how to combine samples from multiple extreme weather systems, given the existence of long-term measurements (e.g. Harris 2001, Kruger et al. 2010). Extreme wind events range from mid-latitude depression systems and channelling winds to thunderstorms and tropical cyclones.

In the case of category (b), since historically many more pressure data than wind measurements have been available, the geostrophic winds can easily be calculated from pressure data over the whole area, which will then be converted into Eurocode wind (Abild et al. 1992, Miller 2003). Efforts in category (b) have inspired the exploration of modelled pressure data in a similar manner, which is an attractive option for locations where measurements are not available (Frank 2001, Larsén and Mann 2009).

Unlike wind-resource assessments, estimating the fifty-year wind requires a significantly longer time series, which is often not available, causing significant uncertainties in making estimates (e.g. Larsén et al. 2015). Category (c) thus becomes a very attractive option. Long-term numerical model data have been made widely available, with spatial resolutions from several km to hundreds of $\mathrm{km}$ and temporal resolutions from 1 to 6 hours. However, these modelled data face a general problem: the numerical smoothing effect embedded in the simulation, which causes extreme wind to be systematically underestimated. Several approaches have been developed to confront this challenge. One is to increase the spatial and temporal resolutions to, for example, $2 \mathrm{~km}$ and $10 \mathrm{~min}$, which are in the vicinity of mesoscale modelling and are associated with high computational costs, given that decades of simulation must be performed. Larsén et al. (2013) have developed a method to calculate extreme wind with a focus solely on severe storms over a long period, thus reducing the computation by $95 \%$. The results of the extreme wind atlas are satisfactory in comparison with measurements. Another approach, the spectral correction method, aims to fix the missing wind variability in the coarse-resolution modelled data over certain frequencies and uses information from the limited measurements to fill in this missing variability through the spectral domain (Larsén et al. 2012). In the absence of measurements, a spectral model derived from measurements was applied. This method was 
used to create an extreme wind atlas for South Africa (Larsén and Kruger 2014) and has been implemented in WEng, ${ }^{10}$ covering most parts of the globe.

While these methodologies are applicable to both onshore and offshore conditions, there are special challenges and advantages in the case of offshore conditions. The challenges are related to the fact that ocean waves are a function of wind and that it is difficult to model this dependence at storm wind conditions. Whereas the waves have a negligible effect on average wind structures, their effect is considerable during strong wind conditions. Wind and wave modelling are often coupled for storms and tropical cyclones (e.g. Liu et al. 2011, Wu et al. 2015). Larsén et al. (2019) used a wind-wave coupled system to draw up an extreme-wind atlas for the waters around Denmark. In general, there is still the challenge of too few measurements being available offshore, making it difficult to validate and improve modelling approaches. The advantage is that, over certain bodies of water, the best-track data for tropical cyclones are available. Ott (2006) used the Holland model and the best-track data to create a fifty-year wind atlas covering the western part of the North Pacific Ocean.

\section{In China}

Western Pacific typhoon activity in summer and autumn brings not only wind power to China's coastal wind farms, but also devastating disasters. Typhoon monitoring data for the past fifty years suggest that typhoons generated east of the Philippines and mainly affecting the southeast coast of China take three active paths: a westward path, a northwest path and a northward path. The distribution of maximum wind speeds once every fifty years along the Chinese coast, based on wind measurements from 205 wind towers taken during 198 typhoons from 2003 to 2010, shows that most of the islands and headlands in Zhejiang, Fujian and Guangdong provinces have a maximum wind speed once every fifty years of 50-55 ms-1. Moreover, the ratio of the maximum wind speed once every fifty years to the annual mean wind speed exceeds the reference value of 5 times the IEC61400-1 standard and can reach 7-10 times on Hainan Island and the Xuwen coast of Guangdong. In addition, analysis of the turbulence characteristics of the coastal near-layer atmosphere under the influence of 44 tropical cyclones produces a number of samples near the typhoon's centre, with turbulence intensities exceeding the IEC61400-1 standard when the wind speed is less than $30 \mathrm{~ms}^{-1}$. In order to produce typhoon-resistant wind turbines, China has organized research on typhoon wind characteristics and compiled a national standard for a 'wind turbine generator system under typhoon conditions'. The standard uses Western Pacific tropical cyclone data from 1949 to 2010 and observation data from 205 wind towers on the southeast coast of

10 WAsP Engineering
China from 2003 to 2010. By analysing the turbulence characteristics of the coastal near-surface atmosphere under the influence of 44 tropical cyclones, the design wind parameters of typhoon-type wind turbines in IEC61400-1 standard were adjusted.

\section{Knowledge gap and outlook}

The calculation of extreme wind is still challenged by our understanding of flow across multiple scales, particularly in the range of a few kilometres to meters, the so-called spectral gap region. This limitation is reflected particularly in complex terrains (e.g. mountainous area, coastal zones) and challenging weather conditions such as tropical cyclones and thunderstorms. Thus, it remains a problem to obtain reliable samples to assess the extreme wind climate and thereafter the distribution of these conditions when calculations cannot be achieved with high confidence. At the same time, whether assessing extreme wind directly or calibrating and verifying models, measurements are rare, since measurement systems often experience technical failures during extreme weather. Long-term, good-quality data are even more difficult to assess.

\section{Non-technical aspects}

The physical wind-power potential is defined by the resources analysed in the preceding sections, in particular the spatial and temporal distribution of (extreme) wind speeds and power. However, the physical potential of the power in the wind has certain geographical, technical, economic and social limitations. As far as possible, these aspects need to be considered in the context of resource assessments for onshore wind. Only then can they provide insights that are useful for relevant stakeholders such as researchers, policy-makers and investors with different levels of influence. This section briefly presents the state of the art in making resource assessments for onshore wind before summarizing the efforts to take the non-technical constraints into account and providing a brief summary of the knowledge gap.

\section{State of the art}

As outlined above, wind resource data and maps are only the first step in assessing the suitability of specific locations for wind-power plants. As well as the wind speed itself, several other factors influence the fraction of power in the wind that can realistically be utilized these are summarized in Table 1 below. In order to inform scientific and policy discussions about the possible contribution and costs of onshore wind, detailed data on their spatial distribution are required. Many studies have analysed these potentials and costs based on a combination of detailed geospatial analysis (wind speeds and land cover), land-suitability criteria and techno-economic turbine characterizations (e.g. Dalla Longa et al. 2018; Bosch et al. 2017; Mckenna et al. 2015). The results of these studies are typically employed by researchers to provide input to energy system models, which explore the economic viability of wind in competition with other energy technologies in the context of long-term energy scenarios (Zeyringer et al. 2018). 


\section{Attempts to consider non-technical constraints}

The studies mentioned above have the limitation that they focus on the technical potential, thereby overlooking many non-technical constraints for onshore wind. Especially relevant is the issue of public acceptance, which includes concerns relating to the environmental impacts, noise, electromagnetic radiation and landscape impacts, the last of these having dominated the research literature on acceptance thus far. This literature shows, for example, that residents are more inclined to accept wind farms if they stand to benefit directly (e.g. as co-owners). Increasing the offset distance from a wind farm can also increase acceptance, as can involving local communities in the development process.

The value of the landscape to different stakeholders is difficult to measure, so data relating to this question are rare. Some studies in the field of regional and spatial planning have employed photographs of different landscapes, which are evaluated in terms of their aesthetic appeal (beauty of the landscape) by members of the public. These studies have provided a geospatial database of landscape beauty, which can be employed to estimate more realistic or feasible wind potentials. Examples include a study of the 'feasible' wind energy potential of the Baden-Württemberg region in Germany (Jäger et al. 2016) and more recently with so-called 'Scenic-or-Not' data for Britain (Mckenna et al. 2020). In addition, Harper et al. (2019) present a multi-criteria decision analysis approach that takes into account the technological, legislative and social constraints in a British context, while Eichhorn et al. (2019) have developed a sustainability assessment framework for possible wind sites, including the environmental, social, technical and economic aspects, and applied it to Germany.

Although evaluations of landscapes provide a basis for evaluating the landscape, other data sources can be employed to evaluate the cost to the householder or other consumer of tolerating landscape modifications produced by onshore wind farms. Combining insights about actually paid compensation with preferences stated in surveys and preferences revealed by actual property prices allows aggregated 'acceptance costs' to be estimated for Denmark (Hevia-Koch and Jacobsen 2019). These acceptance costs can be added to previously determined generation costs to estimate the full cost of acceptance.

Other researchers have employed expert stakeholder workshops in order to arrive at more meaningful potential estimates for onshore wind. For example, Höltinger et al. (2016) present a participatory approach with key stakeholders to consider the effects of socio-political and market acceptance on the techno-economic potential for wind in Austria.

\section{Knowledge gap and outlook}

While progress has been made in accounting for these non-technical dimensions in making assessments of onshore wind resources, further developments are required In particular, these should aim to increase the precision of these factors in the spatial modelling, as well as to improve the consistency and transferability of assumptions in the methods employed in different contexts.

Much of the research discussed above employs location-specific data on the actual or perceived 'value' of landscapes. However, financial evaluations of public acceptance are notoriously uncertain, as well as being person- and location-specific. At the very least, spatially disaggregated data relating to these preferences would be required to draw up a complete balance sheet. These data need to take into account the impact on communities living in the vicinity of new or existing wind farms, as well as calculate the economic value of beautiful landscapes. This would involve taking into account the number or frequency of 'sightings', as well as the actual value of each sighting as inferred from

Table 1 Overview of different potential definitions and their exemplary policy relevance (adapted from) McKenna et al. (2020)

\begin{tabular}{|c|c|c|c|}
\hline Potential term & Defined as... & Affected by, e.g. & $\begin{array}{l}\text { Energy policy } \\
\text { relevance, e.g. }\end{array}$ \\
\hline Theoretical potential & $\begin{array}{l}\text {...the total energy content of wind } \\
\text { globally. }\end{array}$ & $\begin{array}{l}\text { Global climate, surface boundary } \\
\text { layer etc. }\end{array}$ & Generally irrelevant \\
\hline Geographical potential & $\begin{array}{l}\text {...the amount of wind energy } \\
\text { across the total area available for } \\
\text { wind turbines }\end{array}$ & $\begin{array}{l}\text { Terrain/topography, land use, } \\
\text { slope, elevation, distance to coast } \\
\text { etc. }\end{array}$ & Generally irrelevant \\
\hline Technical potential & $\begin{array}{l}\text {...the electricity that can be gen- } \\
\text { erated from wind turbines within } \\
\text { the geographical potential with } \\
\text { a given turbine technology (e.g. } \\
\text { current, future). }\end{array}$ & $\begin{array}{l}\text { Hub height, rotor diameter, power } \\
\text { density (turbine spacing), specific } \\
\text { rotor power, wake effects etc. Also } \\
\text { planning constraints }\end{array}$ & $\begin{array}{l}\text { Wind industry RED, } \\
\text { innovation and mar- } \\
\text { ket dynamics }\end{array}$ \\
\hline Economic potential & $\begin{array}{l}\text {...a subset of the technical poten- } \\
\text { tial that can be realized econom- } \\
\text { ically. }\end{array}$ & $\begin{array}{l}\text { Investment and O\&M costs of } \\
\text { turbines, subsidies }\end{array}$ & $\begin{array}{l}\text { Energy-political } \\
\text { frameworks }\end{array}$ \\
\hline Feasible potential & $\begin{array}{l}\text {...reflecting non-technical con- } \\
\text { straints. }\end{array}$ & $\begin{array}{l}\text { Manufacturing capacity, public } \\
\text { acceptance }\end{array}$ & $\begin{array}{l}\text { Public acceptance, } \\
\text { market barriers, inertia }\end{array}$ \\
\hline
\end{tabular}


its scenic beauty. Exploring the links between landscape beauty and other variables is another potentially promising research area. For example, there is a strong statistical correlation between the outcome of planning applications for onshore wind parks and the scenic qualities of the location (Mckenna et al. 2020).

One starting point for extending these approaches to other contexts could be to identify similarities and differences between acceptance and planning procedures elsewhere (Suskevics et al. 2019). Either a set of images of the environment taken at eye-level is needed, or a relationship between scenic quality and land-use categories (Stadler et al. 2011) or other landscape metrics. For the former, scenic ratings of the images could then be crowd-sourced like for Scenic-Or-Not or estimated using computer vision approaches (Seresinhe et al. 2017). Further crowd-sourced ratings or deep-learning estimates would make it possible to increase data granularity above one photograph per 1 km². Ratings for further photographs would also help ensure that views in different directions were taken into account for each area. This framework could also be enhanced to take into account the size and type of turbine installed, introduce a setback distance to significantly increase acceptance (Betakova et al. 2015) or take into account the experience that local communities already have with wind energy (Van der Horst 2007). It could also include estimates of the potential impact of changes to landscape aesthetics on happiness and health, building on the modelling reported by Seresinhe et al. (2019) to help policy-makers understand the range of trade-offs at play.

\section{Summary}

This chapter has provided a review of both the technical and non-technical aspects of assessing wind resources and the technical aspects of estimating extreme wind. The overall development of methodologies and applications has been described, with a particular focus on China. Significant progress on these topics has been achieved in recent decades as a result of scientific discoveries, computational capacities, technical skills, market demand and international collaboration. Regarding the technical aspect, there are still limitations in our knowledge and challenges in our ability to calculate more accurately; the knowledge gap lies particularly in describing flow across scales, including improving the synoptic field through, for example, data assimilation and improving the downscaling from the mesoscale to the microscale, particularly for challenging terrain and surface conditions. In estimating extreme wind, continuous efforts are required to improve not only statistical approaches but also the physical aspects, such as modelling extreme weather, like tropical cyclones and thunderstorms. Much of the research discussed here accounting for the non-technical dimensions in making resource assessments for onshore wind employs location-specific data on the actual or perceived 'value' of landscapes. As a result, transferring these methods to other contexts relies on relevant spatially disaggregated data. These data need to reflect the impact of new or existing wind farms on communities living in their vicinity, as well as to consider the economic value of beautiful landscapes.

\section{References}

Abild, J. and Nielsen, B. 1991. Extreme values of wind speeds in Denmark. Technical Report M-2842, Risø National Laboratory, Roskilde, Denmark.

Abild, J., Mortensen, N.G. and Landberg, L. 1992. 'Application of the wind atlas method to extreme wind speed data'. Journal of Wind Engineering and Industrial Aerodynamics, 41: pp. 473-484.

Badger, J., Mortensen, N. and Larsén, X. 2010. 'A universal mesoscale to microscale modeling interface tool'. EWEC 2010 Proceedings online. European Wind Energy Association (EWEA).

Badger, J., Frank, H., Hahmann, A.N. and Giebel, G. 2014. Wind-Climate Estimation Based on Mesoscale and Microscale Modeling: Statistical-Dynamical Downscaling for Wind Energy Applications'. J App/ Meteorol Climatol. 53: pp. 1901-1919.

Badger, M., Peña, A., and Hahmann, A. 2016. 'Extrapolating satellite winds to turbine operating heights', J. Appl. Meteorol. Clim. 55: pp: 975-991.

Betakova, V., Vojar, J., and Sklenicka, P. 2015. Wind turbines location: How many and how far?’ Applied Energy, 151: pp. 23-31.

Bosch, J., Staffell, I. and Hawkes, A. 2017. 'Temporally-explicit and spatially-resolved global onshore wind energy potentials'. Energy. 131.

China Meteorological Administration. 2014. The detail investigation and assessment report of wind energy resource in China. Beijing: China Meteorological Press, 2014.5. (in Chinese)

Dalla Longa, F., Kober, T., and Badger, J. 2018. 'Wind potentials for EU and neighbouring countries: Input datasets for the JRC-EU-TIMES Model, EUR 29083 EN', Publications Office of the European Union, Luxembourg. 
Delle Monache, L., Eckel, F.A., Rife, D.L., Nagarajan, B. and Searight, K. 2013. 'Probabilistic weather prediction with an analog ensemble'. Mon Weather Rev, 141: pp. 3498-516.

Draxl, C., Clifton, A., Hodge, B. and McCaa, J. 2015. 'The Wind Integration National Dataset (WIND) Toolkit'. Appl Energy, 151: pp. 355-66.

Eurocode. 1995. 'Eurocode 1, basis of design and actions on structure-Parts 2-4: actions on structure-wind actions'. European Committee For Standardization Technical Report, Rue de Stassart, Brussels.

Eichhorn, M., Masurowski, F., Becker, R., Thrän, D. 2019 'Wind energy expansion scenarios: a spatial sustainability assessment', Energy: 180: pp. 367-375.

Fischereit J., Larsén X. G. 2020. 'Relevance of sea waves and farm-farm wakes for offshore wind resource assessment', presentation at EERA DeepWind'2020, 15-17 January 2020, Trondheim, Norway.

Fitch, A., Olson, J., Lundquist, J., Dudhia, J., Gupta, A., Michalakes, J. and Barstad, I. 2012. 'Local and Mesoscale Impacts of Wind Farms as Parameterized in a Mesoscale NWP Model'. Monthly Weather Review, 140(9): pp. 3017-3038

Frank, H. P., Rathmann, O., Mortensen, N. and Landberg L. 2001. 'The numerical wind atlas - the KAMM/WAsP method'. Forskningscenter Risoe. Risoe-R, No. 1252(EN)

GWEC. 2020. Global wind report 2019.

Hahmann, A., Sile, T. and With, B. 2020. The making of the new European Wind Atlas, Part 1: model sensitivity. Geosci. Model Dev., 13, 5053-5078, 2020, https://doi. org/10.5194/gmd-13-5053-2020

Harper, M., Anderson, B., James, P. and Bahaj, A. 2019. 'Assessing socially acceptable locations for onshore wind energy using a GIS-MCDA approach', International Journal of Low Carbon Technologies, 14: pp. 160-169.

Harris, R.I. 2001. 'The accuracy of design values predicted from extreme value analysis'. Journal of Wind Engineering and Industrial Aerodynamics. 89: pp. 153-164.

Hasager, C., Hahmann, A. and Ahsbahs, T. 2020. 'Europe's offshore winds assessed with synthetic aperture radar, ASCAT and WRF', Wind Energ. Sci. 5: pp. 375-390.

Hevia-Koch, P. and Jacobsen, H. K. 2019. 'Comparing offshore and onshore wind development considering acceptance costs', Energy Policy, 125: pp. 9-19.

Höltinger, S., Salak, B. and Schauppenlehner, T. 2016. 'Austria's wind energy potential - A participatory modeling approach to assess socio-political and market acceptance'. Energy Policy, 98: pp. 49-61.
IRENA. 2020. 10 years progress to action.

IRENA. 2019. Renewable capacity statistics 2019, www. irena.org

Jäger, T., McKenna, R. and Fichtner, W. 2016. 'The feasible onshore wind energy potential in Baden-Württemberg: A bottom-up methodology considering socio-economic constraints', Renewable Energy, 96 (Part A): pp. 662-675.

Kruger, A.C., 2010. 'Wind climatology of South Africa relevant to the design of the built environment' (Ph.D. dissertation). Stellenbosch University http://hdl. handle. net/10019.1/6847

Larsén, X. and Mann, J. 2009. 'Extreme winds from the NCEP/NCAR reanalysis data'. Wind Energy.

Larsén, X., Ott, S., Badger, J., Hahmann, A. and Mann, J. 2012. 'Recipes for Correcting the Impact of Effective Mesoscale Resolution on the Estimation of Extreme Winds', Journal of Applied Meteorology and Climatology, 51: pp. $521-533$.

Larsén X., Badger J., Hahmann A. N. and Mortensen N.G. 2013. 'The selective dynamical downscaling method for extreme wind atlases', Wind Energy, 16: pp. 1167-1182.

Larsén X. and A. Kruger. 2014. 'Application of the spectral correction method to reanalysis data in South Africa', Journal of wind engineering and industrial aerodynamics. 133: pp. 110-122.

Larsén, X., Mann, J., Rathmann, O., and Jørgensen, H. 2015 'Uncertainties of the 50-year wind from short time series using generalized extreme value distribution and generalized Pareto distribution', Wind Energy 18: pp. 59 - 74.

Larsén, X., Du. J., Bolanos R., Imberger M., Kelly M., Badger M. and Larsen S. 2019. 'Estimation of offshore extreme wind from wind-wave coupled modeling'. Wind Energy. 22(8).

Liu, B., Liu, H., Xie, L., Guan, C. and Zhao, D. 2011. 'A coupled atmosphere-wave-ocean modelling system: simulation of the intensity of an idealized tropical cyclone'. Mon. Weather Rev. 139(1): pp. 132-152.

Ma, W., Zhu, R. and Li Z. 2016. 'Study of the short-term wind power forecasting method for complex terrain wind farm based on the CFD dynamical downscaling'. Acta Meteorologica Sinica, 74(1): pp. 89-102. (in Chinese)

Mann, J., Angelou, N. and Arnqvist J. 2017. 'Complex terrain experiments in the New European Wind Atlas,' Philos. Trans. R. Soc. London, 375.

McKenna, R., Ryberg, D. S., Staffell, I., Hahmann, A. N., Schmidt, J, Heinrichs, H., Höltinger, S., Lilliestam, J., Pfenninger, S., Robinius, M., Stolten, D., Tröndle, T., Wehrle, S., Weinand, J. 2020. On the socio-technical potential for 
onshore wind in Europe: a response to Enevoldsen et al. (2019), Energy Policy, 132, 1092-1100

Mckenna, R., Weinand, J. M., Mulalić, I., Petrović, S., Mainzer, K., Preis, T. and Moat, H.S. 2020. 'Improving renewable energy resource assessments by quantifying landscape beauty', Working Paper Series in Production and Energy, IIP, KIT.

Miller, C. 2003. 'A once in 50-year wind speed map for Europe derived from mean sea level pressure measurements'. Journal of Wind Engineering and Industrial Aerodynamics 91: pp. 1813-1826.

Mortensen, N.G., Hansen, J.C. and Badger, J. 2006. Wind atlas for Egypt. Measurements and modelling; 1991-2005. Roskilde: Risø National Laboratory.

Ott, S. 2005. 'Extreme winds in the western North Pacific'. Technical Report Risoe-R-1544 (EN), Risø National Laboratory, Roskilde, Denmark.

Seresinhe, C. I., Preis, T., and Moat, H. S. 2017. 'Using deep learning to quantify the beauty of outdoor places'. Royal Society Open Science, 4

Seresinhe, C. I., Preis, T. and Mackerron, G. 2019. 'Happiness is greater in more scenic locations'. Scientific Reports, 9, 4498.

Stadler, B., Purves, Ross S. and Tomko, M. 2011. 'Exploring the relationship between land cover and subjective evaluation of scenic beauty through user generated content'. In: 25th International Cartographic Conference, Paris, FR, 3 July 2011 - 8 July 2011.
Suskevics, M. 2019. 'Regional variation in public acceptance of wind energy development in Europe: What are the roles of planning procedures and participation?', Land Use Policy, 81: pp. 311-323.

Tammelin, B. 2013. 'Production of the Finnish wind atlas'. Wind Energy 16: pp. 19-35.

Troen, I. and Petersen, E. L. 1989. European Wind Atlas.

Van der Horst, D. 2007. 'NIMBY or not? Exploring the relevance of location and the politics of voiced opinions in renewable energy siting controversies'. Energy Policy 35: pp. 2705-2714.

Veers, P., Dykes, K. and Lantz, E. 2019. 'Grand challenges in the science of wind energy', Science.

Wu, L., Rutgersson A., Sahlée and Larsén, X. 2015. 'The impact of waves and sea spray on modeling storm track and development'. Tellus, 67.

Zeyringer, M., Price, J. and Fais, B. 2018. 'Designing low-carbon power systems for Great Britain in 2050 that are robust to the spatiotemporal and inter-annual variability of weather'. Nat Energy 3: pp. 395-403.

Zhu, R., He, X. F., and Zhou, R. W. 2010. 'The numerical simulation assessment methodology for regional wind energy resources'. Wind energy, 6: pp. 50-54. (in Chinese)

Zhu, R., Wang, Y. and Xiang, Y. 2O2O. 'Study on climate characteristics and development potential of wind energy resources in China'. Acta energiae solaris sinica, in press. (in Chinese) 